\title{
Ranging behaviour of greater flamingos during the breeding and post-breeding periods: Linking connectivity to biological processes
}

\author{
Juan A. Amat ${ }^{a, *}$, Miguel A. Rendón a , Manuel Rendón-Martos ${ }^{b}$, \\ Araceli Garrido ${ }^{\text {b }}$, José M. Ramírez ${ }^{\mathrm{b}}$ \\ ${ }^{a}$ Estación Biológica de Doñana, CSIC, Apartado 1056, E-41080 Sevilla, Spain \\ ${ }^{b}$ Reserva Natural Laguna de Fuente de Piedra, Consejería de Media Ambiente, Junta de Andalucía, E-29520 Fuente de Piedra, Spain
}

\begin{abstract}
Connectivity among habitat patches has mainly been studied in relation to species-specific behaviours. However, the movements of animals among patches may have different functions, and tolerance to gaps between habitat patches may vary between these functions. We tracked the movements of greater flamingos during the breeding and post-breeding periods with the aim of illustrating how the degree of connectivity may vary depending on the biological processes underlying the movements between wetlands. Most foraging sites used by breeding adults in a colony in southern Spain were within $200 \mathrm{~km}$ of the colony site, although some birds eventually moved $400 \mathrm{~km}$. After the breeding season, the adults remained for several weeks in specific wetlands, moving to other sites located 280-2100 km away to overwinter. During these movements the birds may use stopover sites, the conservation of which may be critical to facilitate long-range movements. Our results suggest that wetland connectivity during chick rearing does not seem to be determined by whether or not central-place foraging flamingos are able to reach wetlands located at the longest distance that they are able to fly during non-stop flights $(>1000 \mathrm{~km})$, but by whether they are able to sustain the energetic costs derived from frequent commuting. In contrast, long-distance movements were occasionally undertaken during the post-breeding period. The energetic costs of such flights could be paid by flamingos because these movements were infrequent. Thus, in the case of flamingos, connectedness thresholds between wetlands vary depending on the biological process involved (chick rearing or post-breeding movements). This emphasizes the need to consider different types of connectivity in conservation planning.
\end{abstract}

Keywords: Wetland connectivity; Functional connectivity; Connectedness thresholds; Mediterranean wetlands; Flamingos; Waterbirds; Stopover sites

\section{Introduction}

Many species utilize resources that are distributed among patches. The concept of connectivity was introduced by landscape ecologists to characterize the "degree to which the landscape facilitates or impedes movement among resource patches" (Taylor et al., 1993). Implicit in this definition is a recognition that

\footnotetext{
Corresponding author. Tel.: +34 95 4232340; fax: +34 954621125.

E-mail address: aguilar@cica.es (J.A. Amat).
}

the movements of individuals among patches are determined by both landscape structure and the behaviour of species. Connectivity has mainly been studied in relation to species-specific dispersal behaviour. However, the movements that animals perform between habitat patches are not only related to the dispersal capabilities of individuals, but may also be related to other functions such as the daily acquisition of resources from central sites (nests or roosts), or seasonal migratory events (Haig et al., 1998; Dobson et al., 1999; Webster et al., 2002). As such, tolerance to gaps between habitat 
patches may differ depending on the type of movements. For instance, the frequency with which movements are performed may restrict the movements' range due to energetic constraints. Because of these differences in the types of movements that animals perform, different types of functional connectivity should be distinguished, and acknowledging this may be crucial to the successful implement action of conservation plans (Webster et al., 2002).

In this study we document the ranging behaviour of greater flamingos Phoenicopterus roseus during different phases of the annual cycle to illustrate how the degree of connectivity may vary depending on the biological processes underlying the movements between wetlands. Greater flamingos are major components of the avifauna of saline and brackish shallow wetlands around the Mediterranean. The largest colony of this species in Spain is located at Fuente de Piedra lake, where 500-19,500 pairs bred during 1977-1999 (Rendón et al., 2001). In this lake water levels exhibit considerable variations, both within as well as between breeding seasons (Rendón-Martos, 1996). During most years, the lake dries out well before the chicks fledge, so that the adults have to use other wetlands to forage, located within $200 \mathrm{~km}$ of Fuente de Piedra (Rendón-Martos et al., 2000). As greater flamingos perform movements among wetlands mainly during the night (Brown, 1975; Rendón-Martos et al., 2000; McCulloch et al., 2003), wetlands located at distances exceeding one night of flight could not be reached, and therefore the degree of connectivity between the breeding site and foraging sites may be an important determinant of wetland use by greater flamingos during the chick provisioning period. Based on observations on the numbers of birds arriving to and departing from Fuente de Piedra lake on a daily basis, Rendón-Martos et al. (2000) surmised that some birds may arrive at the colony, feed their chicks, and then return to foraging sites in the same night. Little is known, however, on the time that birds remain at foraging sites between visits to the colony to provision their chicks, or whether individual birds remain faithful to foraging sites during the chick provisioning period. The study of ranging behaviour is of interest because both flight distances and the frequency of provisioning trips may constrain energy budgets, and thus compromise chick survival (Weimerskirch et al., 1997). Rendón-Martos et al. (2000) suggested that some individuals may desert whilst provisioning chicks late in the breeding season. This may indicate that commuting is costly, and that not all individuals can assume those costs. Because greater flamingos are sexually dimorphic in size, with males being larger than females (Cramp and Simmons, 1977), there would be relatively greater demands on females than on males during chick rearing, so that females should reduce their work load so as not to compromise their survival (e. g., Cézilly et al.,
1994; Berrow and Croxall, 2001). In fact, there is evidence that there are sex-related differences and survival costs of breeding in greater flamingos (Tavecchia et al., 2001). Therefore, we would expect that the time that birds remain at foraging sites between consecutive provisioning trips should be inversely related to their body size.

Little is known on the movements of adult greater flamingos during the post-breeding period. It is important to identify the areas utilized by adults after breeding, because such areas may be critical for moulting or overwintering, and thus a link between breeding and wintering sites may be essential to understand the dynamics of the population and to design conservation measures (Haig et al., 1998). In addition to their implications on population dynamics, such movements may also have important implications on the functioning of aquatic ecosystems, e.g. facilitating the dispersal of propagules between wetlands (Figuerola and Green, 2002).

Haig et al. (1998) stressed the need for studying both within- as well as between-season movements of individual birds among multiple sites for conservation purposes. In this study we employed both satellite and VHF telemetries to monitor the movements of greater flamingos during the chick rearing and post-breeding periods. The aim was to determine the patterns of wetlands use during these periods in order to provide arguments on which to base the choice of reserve sites. In particular, we will discuss on the importance of the spatial location of sites for the conservation of colonies of waterbirds that rely on distant food sources, as well as on the need to incorporate connectivity into conservation planning, especially when the use of sites exceeds geopolitical boundaries and/or several sites are required to meet long-term needs (Haig et al., 1998; Arengo and Baldassarre, 1999; Amezaga et al., 2002; Briers, 2002; Webster et al., 2002).

\section{Methods}

\subsection{Field procedures}

Adult greater flamingos were captured at Fuente de Piedra lake $\left(36^{\circ} 06^{\circ} \mathrm{N}, 4^{\circ} 45^{\circ} \mathrm{W}\right)$ in early or mid-July 2000-2002, once the lake had dried out. This ensured that nearly all adults present at the lake at that time were breeding birds, as no chicks had fledged at that time and the adults were performing frequent foraging trips to other wetlands. After feeding the chicks, the adults that remained during diurnal hours in the colony site moved to the mouth of a stream that diverted into the lake. This stream flooded 3-5 ha and is located about $1 \mathrm{~km}$ from the créche site. Adults spent most of the diurnal hours resting, and utilized the flooded site mainly for 
bathing and drinking, and less frequently for feeding. In the late afternoon the adults departed from the flooded site to the colony site to feed their chicks, and from there departed to foraging sites around sunset. By placing leg snares on the ground, we captured adults as they entered the flooded site (for a similar procedure see McCulloch et al., 2003).

In 2000 we trapped eight adults and attached a $80-\mathrm{g}$ battery-powered, platform transmitter terminals (PTT), manufactured by North Star Science and Technology (Columbia, MD). The transmitters measured $66 \cdot 36 \cdot 23 \mathrm{~mm}$, with an antenna $230 \mathrm{~mm}$ long, and had a continuous duty-cycle. Transmitters were attached using a teflon harness. One transmitter failed shortly after attachment, but the remaining 7 were tracked for an average of 143 days.

Because of limited financial budgets we used VHP transmitters, instead of PTTs, in 2001 and 2002. We trapped 10 adult birds in 2001, and five birds in 2002. To these we attached 50-g battery-powered VHP transmitters manufactured by Televilt Int. AB (Lindesberg, Sweden) with an expected life of 13 months. These transmitters were attached using a Tygon harness. The transmitters measured $65 \cdot 40 \cdot 25 \mathrm{~mm}$, and had a $450 \mathrm{~mm}$ long antenna. We used a four-element Yagi antenna to track flamingos in the main wetlands utilized by greater flamingos in Andalusia (southern Spain). Most wetlands were visited every 1-2 weeks during the chick provisioning period, and every 1-3 months during the rest of the year. The arrivals of adults to Fuente de Piedra to provision the chicks, as well as departures from the lake, were monitored using an automatic scanning receiver and datalogger (RX-900, Televilt). The receiver was programmed to scan continuously the range of frequencies, which was done every $16 \mathrm{~min}$.

Attachment of transmitters may influence the behaviour of the study subject. By being externally attached, the transmitters may have increased the birds' aerodynamic resistance, increasing energy expenditure (e.g., Godfrey et al., 2003). However, two lines of evidence indicate that the effect of transmitters on flamingos may be small. First, there was no significant difference between the number of days that greater flamingos with and without transmitters spent in foraging sites between consecutive visits to the lake during the chick provisioning period (see below). And second, flamingos with transmitters were recorded breeding 1-2 years after having been marked (see below).

All flamingos with transmitters attached were measured (lengths of culmen, wing and tarsus) and their body masses recorded at the moment of capture. Mean body masses of these adults were $2683 \pm$ (s.d.) $304 \mathrm{~g}$ $(n=23)$. All these adults were also provided with darvic rings with alphanumeric codes for individual identification with a telescope. We assigned sex to most individuals (17 of 18) captured in 2000 and 2001 based on body size. We used DNA analysis (Bertault et al., 1999) to determine sex in 2002.

\subsection{Analyses of data}

Data provided by PTTs were obtained from the Argos system, which assigns a quality index (the location class [LC]) to each location (Argos, 2003). The quality of the locations is based on the number of messages received during a satellite pass. The accuracy of LC3 is $<150 \mathrm{~m}$ from the exact location, LC3 is $150-350 \mathrm{~m}$, LC1 is $350-1000 \mathrm{~m}$, and LC0 is $>1000 \mathrm{~m}$. Argos also provides LCs A and B, with an unspecified level of accuracy, although this does not necessarily imply that these LCs are less accurate that other LCs (White and Sjöberg, 2002).

During the chick rearing period, when the lake is usually dry (June-August), the adult flamingos in Fuente de Piedra are located either at the créche site or at the flooded site. We estimated the accuracy of Argos locations as the shortest distances between the locations reported by Argos and either the centre of the flooded site or the centre of the créche site, the only two sites utilized by flamingos at the lake in summer months. This procedure showed that the accuracy of locations decreased from LC3 to LCB (Fig. 1), and that the accuracies of the most precise LCs $(3,2,1)$ given by Argos corresponded with those recorded directly by us. We received a mean of 1877 locations per bird $(n=7)$, of which $9.3 \%$ were of LC3, $19.0 \%$ of LC2, $25.1 \%$ of LC1, $13.7 \%$ of LC $0,16.4 \%$ of LCA, and $16.3 \%$ of LCB. The accuracy of fixes is less relevant to the documention of longdistance movements than more detailed aspects such as small-scale movements within sites (Hays et al., 2001). We used LCs 3, 2, and 1 to determine wetland

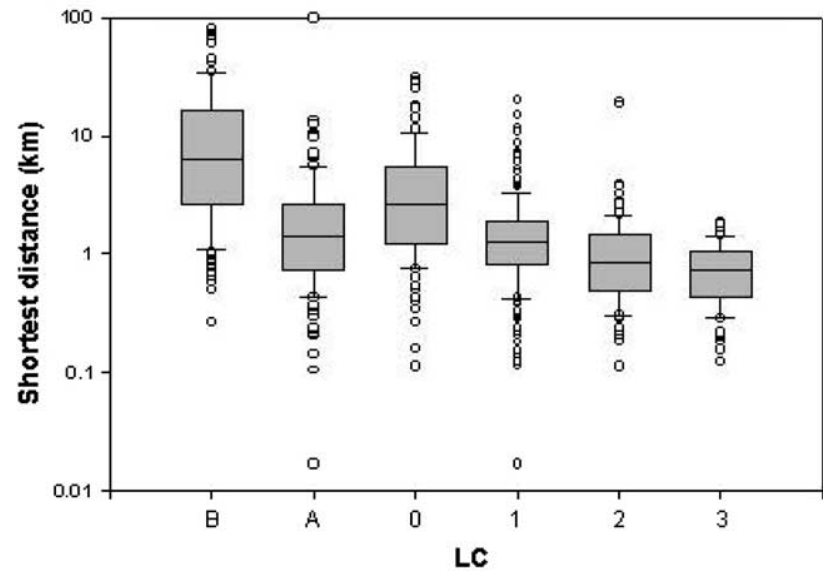

Fig. 1. Shortest distances (median $\pm 75 \%$ (boxes) and 95\% (lines) confidence intervals) between locations reported by Argos and fixed sites utilized by greater flamingos in Fuente de Piedra lake during the chick rearing period, according to location class (LC). Open symbols denote outliers. 
use. In addition to the latter, we also used LCs 0 and A to determine the dates of departure from and arrival at wetlands, as well as the fixes during movements. We used all LCs, except B, to estimate travel speeds. We also excluded the locations of 7 flights $(18.9 \%$ of 37 recorded) because estimated travel speeds between two consecutive fixes were unrealisticaly low $\left(<30 \mathrm{~km} \mathrm{~h}^{-1}\right)$ or high $\left(>90 \mathrm{~km} \mathrm{~h}^{-1}\right)$.

To identity the localities used by greater flamingos, we used a database of geographic coordinates available online (http://www.wayhoo.com). Distances between locations were calculated as great circle distances, using R Package 4.0 (Casgrain and Legendre, 2001). We utilized DMAP version 7.0 to generate maps of the locations of wetlands used by flamingos.

To derive a measure of the structural size of flamingos, we performed a principal components analysis with the three linear measurements (culmen, wing and tarsus) of all captured birds, and used the first principal component (PC1) as an index of structural body size. PCI explained $48 \%$ of the variance, and the loadings factors of this component were positively correlated $(\mathrm{P}<0.05)$ with tarsus and bill lengths. Our aim was to test whether the time that birds remained at foraging sites during the chick provisioning period was affected by body size.

\section{Results}

\subsection{Wetlands use during the chick rearing period}

Twenty-two greater flamingos fitted with transmitters utilized seven wetlands to forage during the chick rearing period (one bird disappeared after being marked in early July and was not relocated until November). The main site was the Guadalquivir marshes area, a wetland complex utilized by 20 birds ( $91 \%$ of 22$)$, located about 130-160 km west of Fuente de Piedra (Fig. 2). Of those birds, 17 were always recorded in the Guadalquivir area, but the other three used other wetlands during successive trips to foraging sites. The first of these three (AjJ7) was also recorded at Odiel marshes $(200 \mathrm{~km}$ west of Fuente de Piedra), Salinas de Cabo de Gata $(230 \mathrm{~km}$ east of the breeding site), El Hondo and Salinas de Santa Pola (390 km north-east of Fuente de Piedra), as well as at Gobierno lake (50 km west of Fuente de Piedra). This bird stopped for a day at Cabo de Gata when moving from Fuente de Piedra to Santa Pola, but made the return trip in a single night (see Fig. 3). Another individual utilized for a brief period the Guadalquivir marshes, and was mainly recorded at Cádiz Bay (140 km south-west of the breeding site). Finally, the third of these flamingos recorded at the Guadalquivir marshes also utilized the

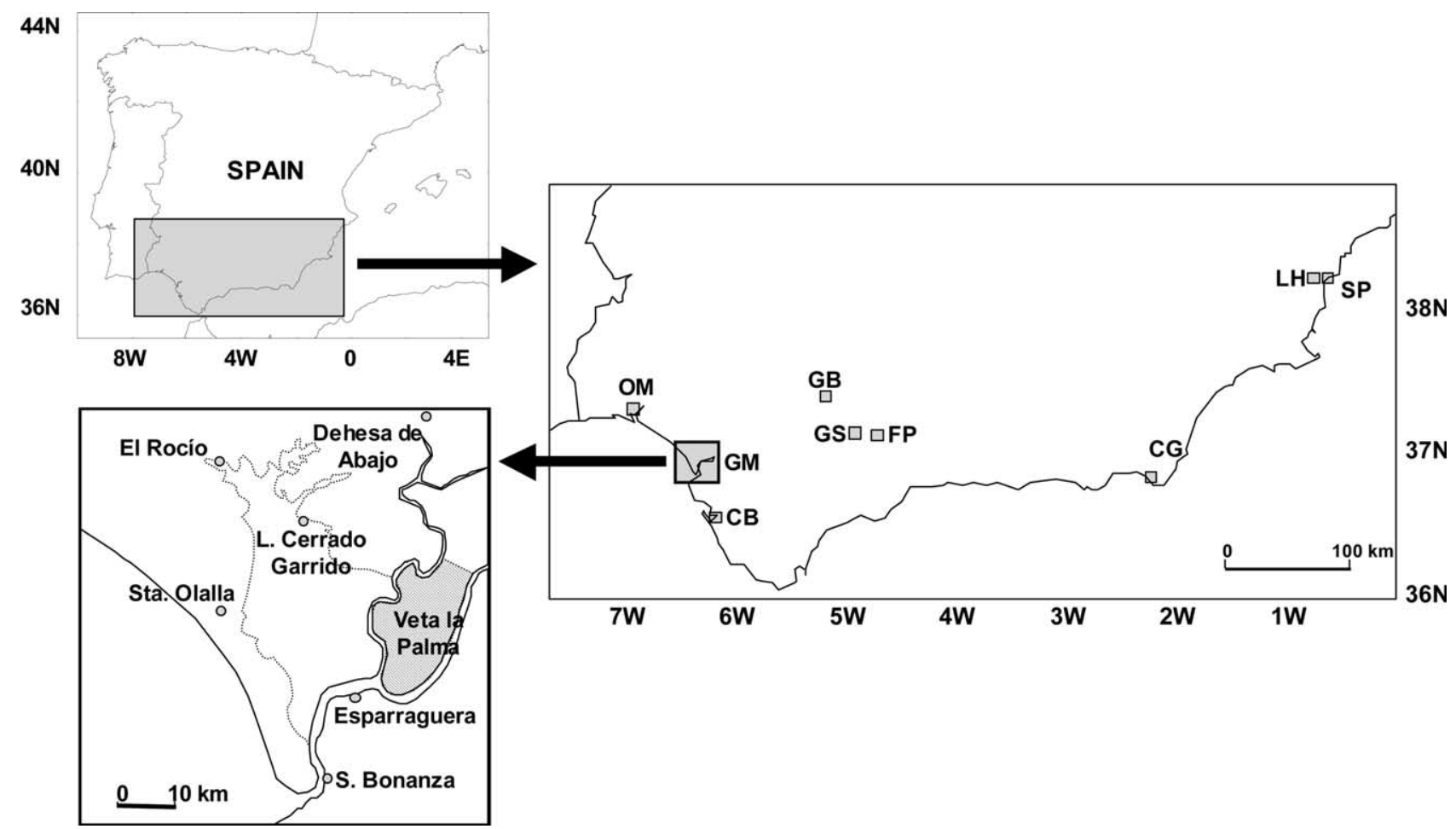

Fig. 2. Location of wetlands in which greater flamingos breeding in Fuente de Piedra lake foraged during the chick rearing period. Codes for wetlands are: FP = Fuente de Piedra lake; GS = Gosque lake; GB = Gobierno lake; GM = Guadalquivir marshes; $\mathrm{CB}=\mathrm{Cádiz} \mathrm{Bay;} \mathrm{OM=Odiel}$ marshes; $\mathrm{CG}=$ Salinas de Cabo de Gata; $\mathrm{SP}=$ Salinas de Santa Pola; $\mathrm{LH}=$ El Hondo. The sites used within the Guadalquivir marshes area are also shown (open circles and shaded area). 

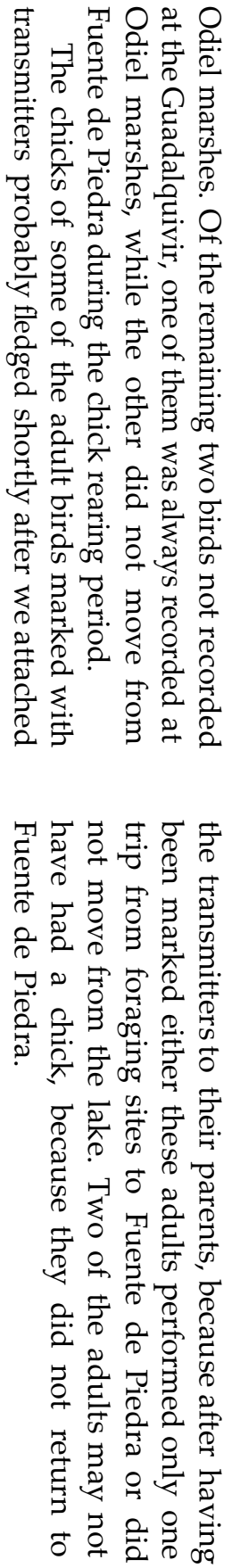

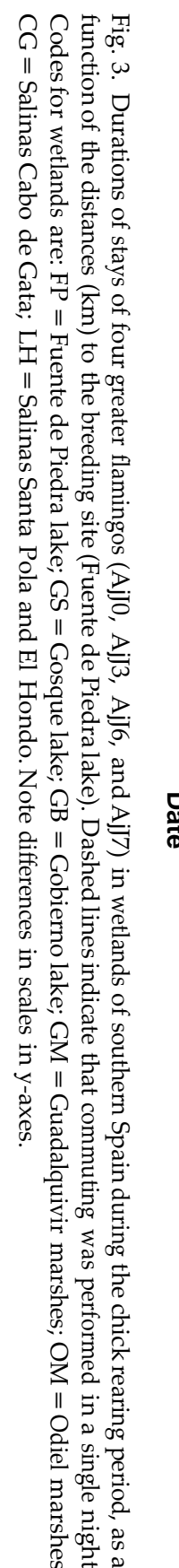

는

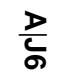

$\frac{D}{\dot{\omega}}$

$\frac{D}{6}$

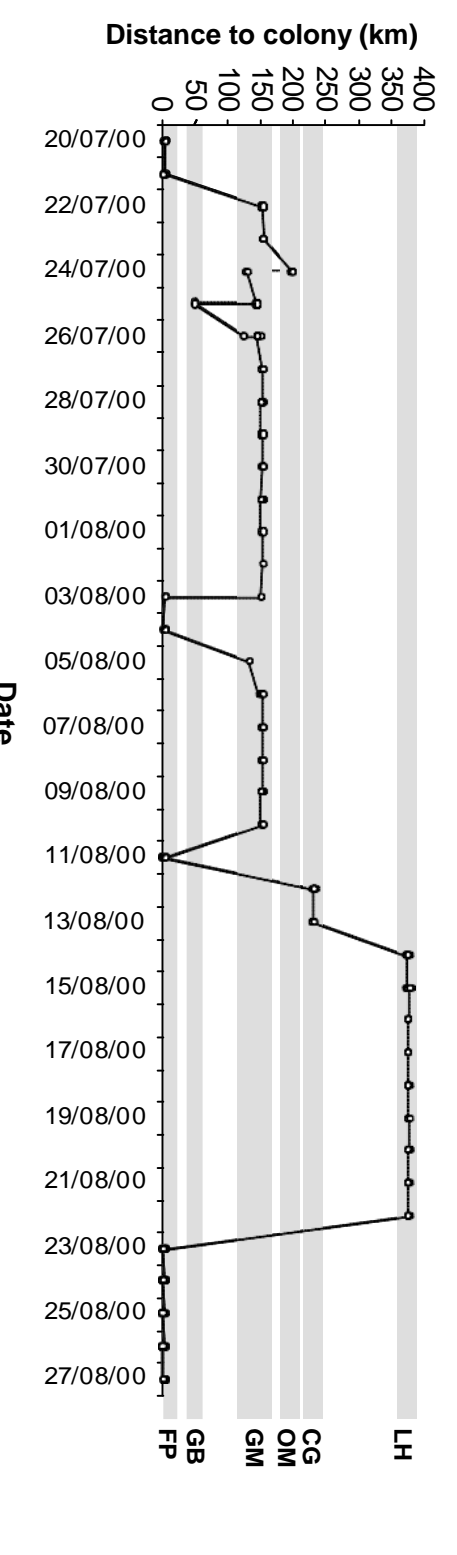

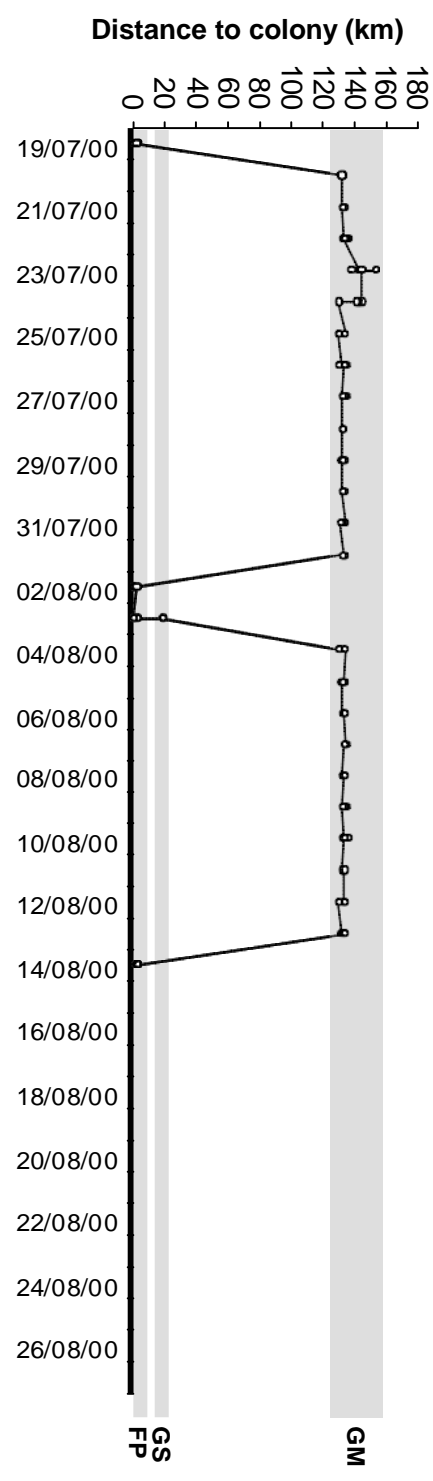

\section{Distance to colony $(\mathrm{km})$}

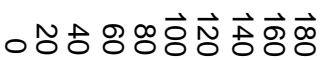

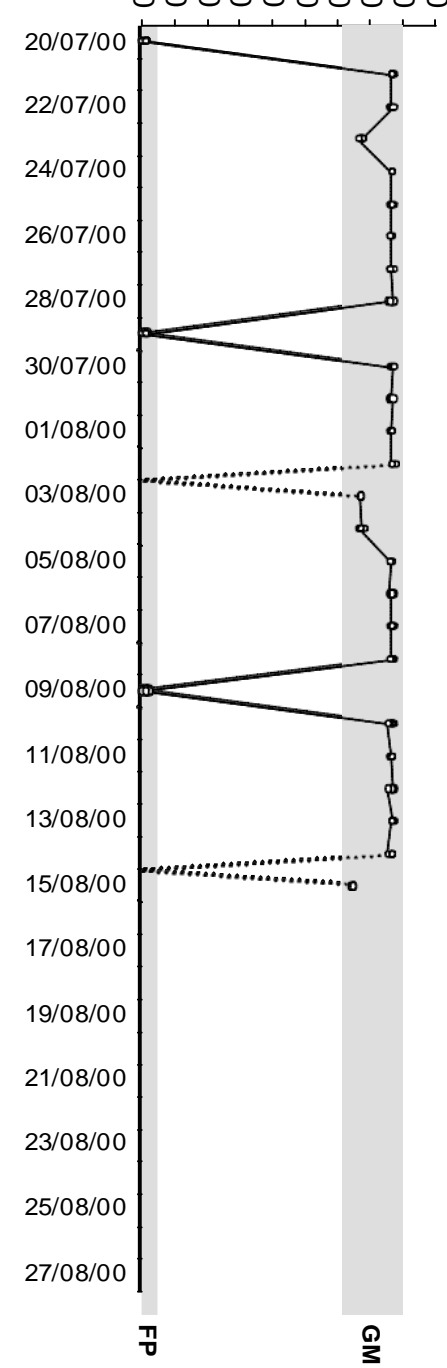

26/07/00 28/07/00 30/07/00 01/08/00 $03 / 08 / 00$ 05/08/00 07/08/00 09/08/00 11/08/00 क् $15 / 08 / 00$ $17 / 08 / 00$ 19/08/00 $21 / 08 / 00$ 23/08/00 25/08/00 27/08/00 ] Tु 


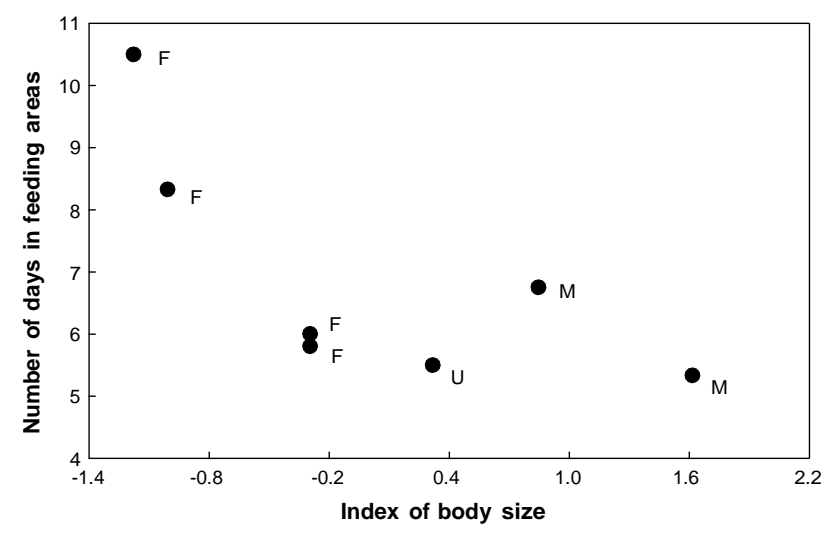

Fig. 4. Mean number of days that greater flamingos spent in foraging sites between visits to Fuente de Piedra lake to provision their chicks in relation to adult body size. The index of body size was obtained as the first principal component scores from a principal components analysis of culmen, tarsus and wing lengths. $F$ beside data points denote females, $\mathrm{M}$ males, and $\mathrm{U}$ undetermined sex.

Individual flamingos exhibited different patterns of permanency at foraging sites between visits to the lake to provision their chicks (Fig. 3). Of the parents that performed at least two provisioning trips, the mean length of stay at foraging sites between two consecutive provisioning trips was $6.9 \pm$ (s.d.) 1.9 days $(n=7)$. The length of stay at foraging areas of birds individually marked with plastic rings $(6.1 \pm 2.7$ days, $n=153$; authors' unpublished data) did not differ significantly from that of birds marked with transmitters (MannWhitney U-test, $\mathrm{U}=380, \mathrm{P}=0.192$ ). The length of stay at foraging areas was negatively correlated with body size (Spearman correlation, $\mathrm{r}_{\mathrm{s}}=-0.77, \mathrm{n}=7, \mathrm{P}=$ 0.041; Fig. 4). Females remained longer at foraging sites $(7.7 \pm 2.2$ days, $n=4)$ than males $(6.0 \pm 1.0$ days, $n=2)$, though due to small sample size the differences could not be analysed statistically. After arriving at the breeding site, the adults $(n=7)$ spent $1.3+0.7$ days there before returning to foraging sites. One of the flamingos tagged with a satellite transmitter made provisioning trips from foraging sites to Fuente de Piedra, and then returned to foraging sites in the same night (Fig. 3). This was also confirmed in another case of a bird fitted with a VHP transmitter.

\subsection{Post-breeding movements}

After breeding, seven flamingos with PTTs were monitored until late November to mid December, when batteries failed. In contrast to the breeding season, movements between wetlands during the post-breeding period were not so frequent. Three of the birds were in the marshes of the Guadalquivir when batteries failed, but the other four birds left Spain in late summer or autumn. Three of these birds moved to Algeria or Tunisia
(Fig. 5(a) and (b)). Distances travelled during non-stop flights by these birds during these displacements varied 228-564 km, and stopover sites utilized by these birds included a reservoir, commercial salt pans and coastal lagoons. One of these birds apparently stopped to rest at sea for a few hours near the coast, $89 \mathrm{~km}$ east of Algiers (AG4 in Fig. 5(b)).

The remaining flamingo with PTT moved from SW Spain to the Banc d'Arguin in NW Mauritania in two non-stop flights of 959 and $1139 \mathrm{~km}$, respectively (Fig. $5(\mathrm{c}))$. It stopped to rest for $8-9 \mathrm{~h}$ at the mouth of a stream (MO in Fig. 5(c)).

When performing long-range movements from southern Spain to African wetlands, the flamingos stopped first in more permanent wetlands (e.g., Salines d'Arzew by AjJ7; Sarno reservoir by AjJ6; Soliman lagoon by AjJ1), rather than going first to temporary wetlands in which conditions would have been more unpredictable (e.g., Sebkha d'Oran by AjJ7; Sebkhet Sedjoumi by AjJ1) (Fig. 5(a) and (b)).

Of the 15 birds fitted with VHF transmitters, five were recorded at the marshes of the Guadalquivir (Veta la Palma; see Fig. 2) until October-November or January. One bird was recorded during September in the Guadalquivir marshes area and during November at Cádiz Bay, but was undetected afterwards. Two individuals were recorded at Odiel marshes during SeptemberOctober, one of which was relocated in the Guadalquivir marshes in October and November, while the other was relocated at Ballestera lake (Sevilla province) in February. A bird disappeared form Andalusia in summer, but was present in the Guadalquivir marshes from mid-winter onwards. Another bird remained until October at Fuente de Piedra and was recorded in the Guadalquivir marshes in January. The remaining four birds disappeared from Andalusia in late summer, although one of them was recorded for a short period in the marshes of the Guadalquivir in November.

For distances $<200$ or $>800 \mathrm{~km}$ the flamingos flew at $60-70 \mathrm{~km} \mathrm{~h}^{-1}$ whereas when they moved intermediate distances they reached $50-60 \mathrm{~km} \mathrm{~h}^{-1}$. The maximum speed recorded was $90 \mathrm{~km} \mathrm{~h}^{-1}$ One bird (AjJ3) flew without stopping for $15 \mathrm{~h}$.

All the flamingos that had been marked with PTTs, except the one that moved to NW Mauritania, were recorded at Fuente de Piedra in the following spring after marking (identified by their darvic rings). Ten of the 15 flamingos with VHF transmitters were recorded also at Fuente de Piedra during the spring following the breeding season in which they were marked.

We confirmed breeding of at least five flamingos that had a transmitter attached a year after marking. Based on movements between Fuente de Piedra and other wetlands after the créches had been established, we infer breeding of three additional birds. Thus, at least 35\% of the birds bred the year after they were marked. 
(a)

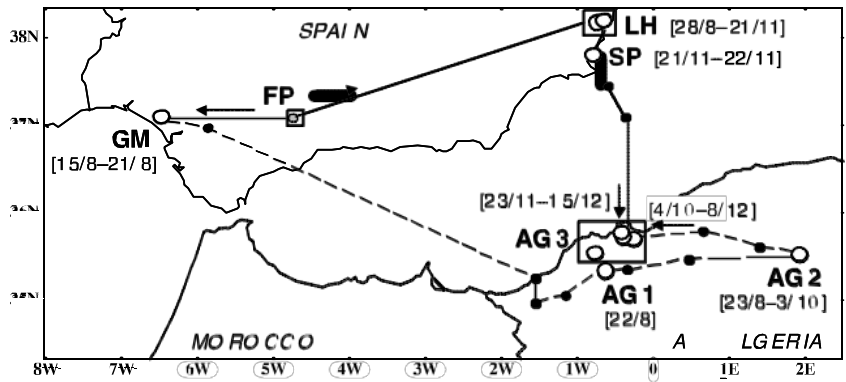

(b)

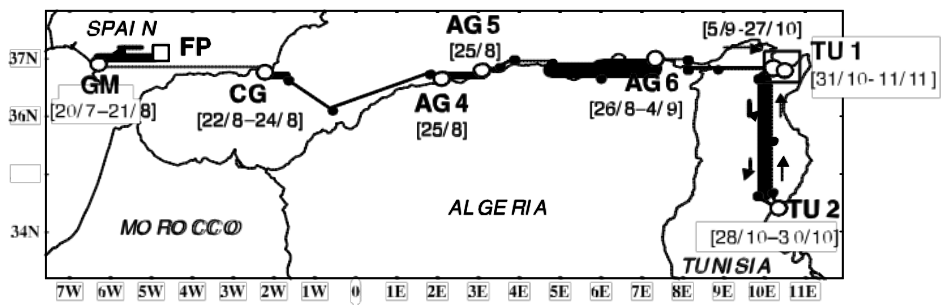

(c)

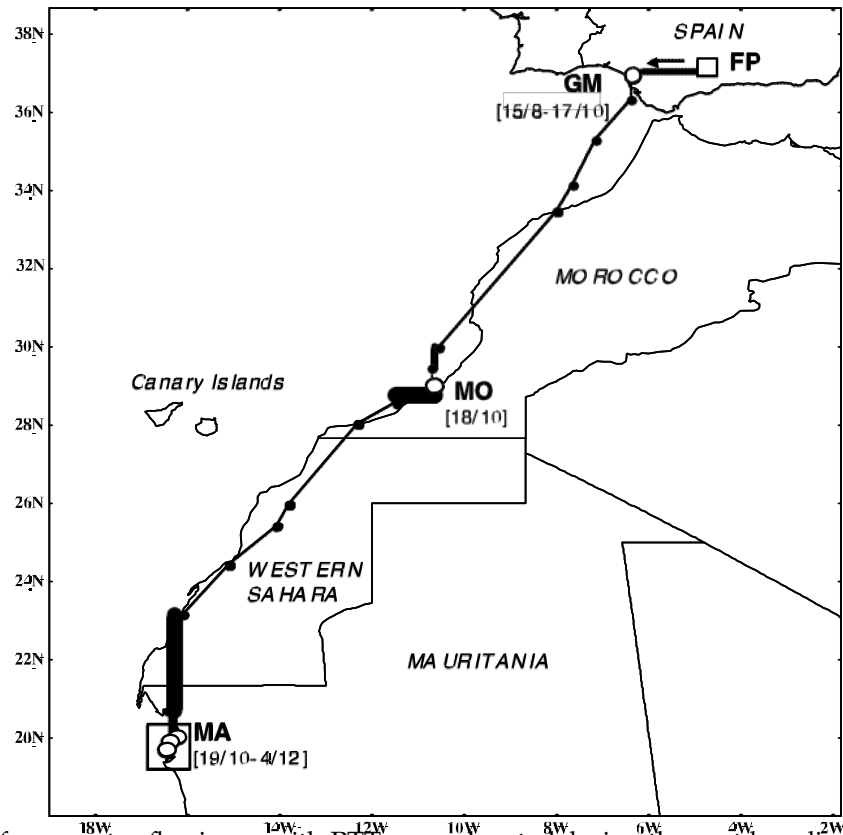

Fig. 5. Sites and dates in which four greater flamingos ${ }^{2}$ with PFTs were located during the post-breeding period. Tracked individuals were: (a) AjJ7 (solid line) and AjJ6 (dashed line); (b) AjJ1; and (c) AjJ3. Large open dots denote that the birds were at land, and small closed dots that the birds were flying. Arrows indicate directions of movements. Codes for sites are: AG1 = Sarno reservoir; AG2 = Telli area; AG3 = Oran area (including Salines d'Arzew, Sebkha d'Oran, and Telamine lake); AG4 = resting at sea; AG5 = Algiers area; AG6= Guerbes-Senhadjia wetlands complexes; $\mathrm{CG}=$ Salinas de Cabo de Gata; FP = Fuente de Piedra lake; GM = Guadalquivir marshes; $\mathrm{LH}=$ El Hondo and Salinas de Santa Pola; MA = Banc d'Arguin (including Tafarit Cape, and louik, Trida and Kiji Islands); MO = mouth of Oued Bou Issafene; SP = Salinas San Pedro del Pinatar; TU1 = Tunis area (including Soliman lagoon and Sebkhet Sedjoumi); TU2 = Iles Kneiss marshes.

\section{Discussion}

\subsection{Ranging behaviour of flamingos}

Flamingos are adapted to use shallow wetlands in which variations in water levels are very dynamic. As a consequence, flamingos may have to shift foraging locations rather frequently (e.g., Baldassarre and Arengo, 2000). Although some of the flamingos that we tracked utilized 2-6 wetlands during the breeding peri- od, others exhibited a strong fidelity to the wetlands where they foraged. Most wetlands used by flamingos during our study have been transformed by humans (fish farms, commercial salt pans), and in such wetlands water levels are artificially maintained, thus allowing their use by waterbirds for extended periods.

The wetlands utilized by greater flamingos during the chick provisioning period were usually within $200 \mathrm{~km}$ of the breeding lake (see also Rendón-Martos et al., 2000), although the birds were also able to reach wetlands as 
far as $400 \mathrm{~km}$. Brown (1975) and Simmons (1996) indicated that flamingos may fly $500-640 \mathrm{~km}$ in a night. During the chick provisioning period a night at Fuente de Piedra lasts about $10 \mathrm{~h}$, so if during their nocturnal movements flamingos fly at a speed of $50-70 \mathrm{~km} \mathrm{~h}^{-1}$ they could move from wetlands located at $>500 \mathrm{~km}$ from Fuente de Piedra, thus supporting the assertions of. those authors. In fact, our data on satellite tracking have shown that they moved about $400 \mathrm{~km}$ in one night.

Simmons (2000) stated that flamingos may fly $2000 \mathrm{~km}$ without stopping, but this needs confirmation. Our results confirm Brown's (1975) suggestion that when distances between origin and destination sites are very long (>900 km), flamingos use other wetlands in between to rest (e.g., individuals AjJ1 and AjJ3, Fig. 5).

Some of the individuals tagged with VHF transmitters remained during winter in wetlands located within $200 \mathrm{~km}$ of Fuente de Piedra lake, and moved the next spring to this lake. Other individuals with VHF transmitters were not recorded during winter, but were relocated during the next spring in Fuente de Piedra, suggesting that such individuals could have spent the winter in wetlands located within one or two journeys of flight to Fuente de Piedra. Indeed, individuals with PTTs that spent the winter in Algeria or Tunisia were recorded the following spring in Fuente de Piedra, but not the individual that moved to Mauritania. This suggests that the individuals that breed in a given year in Fuente de Piedra had spent the previous winter in wetlands located within two journeys of flight to the breeding site. This would allow such individuals to move quickly to the nesting site in late winter or early spring to attempt breeding, which may be very important in order to acquire a site in which to nest, given that competition for nesting sites is high (Rendón et al., 2001).

\subsection{Wetland connectivity and biological processes}

It is important to distinguish between different types of functional connectivity when studying avian movements. In the particular case of flamingos, wetland connectivity during chick rearing should be distinguished from "migratory or dispersal" connectivity. Wetland connectivity during the chick rearing period does not seem to be determined by whether or not central-place foraging flamingos are able to reach wetlands located at the maximum distance that they are able to move during non-stop flights, but by whether they are able to sustain the energetic costs derived from frequent commuting during the whole chick provisioning period (i.e., about 3 months). In this last case the range of movements should be determined by energetic constraints, which would restrict the distances that flamingos may fly during frequent provisioning trips. Evidence for this was that the duration of provisioning trips was body size-related, suggesting that the smaller individuals (i.e., females) could be reducing their work load. Even with such reduction of the work load, some individuals are apparently unable to attend their chicks during the late chick provisioning period, and they then have to desert their chicks (Rendón-Martos et al., 2000; see also Cézilly et al., 1994). In the greater flamingo the males, but not the females, increase the duration of feeding bouts to their chicks as the chicks grow, which has been suggested to be due to females being physiologically stressed because of reproduction, and be unable to adjust to the greater demands of older chicks (Cézilly et al., 1994). This different pattern of chick provisioning by males and females may not be the result of a sexual conflict over parental care, since reduced food provisioning rates during the chick period lead to increased mortality during the post-fledging period (authors' unpublished data).

As opposed to regular and frequent movements during the breeding period, the long distances that flamingos moved during the post-breeding period were occasionally undertaken. The energetic costs of such flights could be paid by flamingos because these movements were infrequent.

\subsection{Implications for conservation}

The apparent inability of greater flamingos to perform frequent flights between very distant wetlands during the chick provisioning period may explain the complete failure of some breeding colonies following the dry out of wetlands in which breeding took place (e.g. Berry, 1975), in spite of other wetlands in which flamingos could potentially have foraged being located within $500 \mathrm{~km}$ of those breeding sites. Such distances might have potentially been covered by flamingos in non-stop flights (Fig. 5; Brown, 1975; Simmons, 2000). However, such distance likely exceeds connectedness thresholds between wetlands' during frequent commuting. This emphasizes the need of conserving wetlands within connectedness thresholds during the breeding period (usually $6200 \mathrm{~km}$ ), for the successful fate of colonies that rely on distant food sources.

The results of our study show that greater flamingos stopped to rest for a few hours in small wetlands during long-range movements between major wetland complexes. Therefore, during dispersal or migration, wetland connectivity may depend not only on the distance between two sites, but also on the presence of stepping-stones, whose protection may be essential to facilitate very long-range movements. The conservation of such stopover sites may contribute to metapopulation persistence. Usually, the number of individuals of a species in a given area is one of the factors that may affect the declaration of such an area as protected. The number of individuals that at a given moment use a stopover 
site during migration periods may be small, yet the turnover of individuals at such a site may be high, even during short time periods (e.g. days or weeks), as our data on flamingos suggest. As such, the identification of stopover sites utilized by greater flamingos during longrange movements may be essential to design a reserve network that may facilitate metapopulation processes. Because the spatial scale of the movements of greater flamingos exceeds geo-political boundaries (Johnson, 1997), it seems evident that international cooperation is needed to conserve the greater flamingo metapopulation in the southwestern Palearctic, as has been suggested for other highly migratory species (Harrington et al., 2002).

In summary, though it is acknowledged that connectivity is a function of the dispersal ability of organisms to link habitat patches across the landscape, this ability is usually considered as a fixed property of the organism involved (but see With, 1994). Nevertheless, depending on the biological process underlying these movements, a given species may have different perceptions as to whether habitat patches are connected or not. In the particular case of flamingos, between-wetland crossing ability is greater during post-breeding dispersal that during chick-rearing, and both of these different types of connectivity should be considered in conservation planning.

\section{Acknowledgements}

Funds from ENDESA Cogeneración y Renovables S.A., and GAMESA Energía S.A. allowed satellite tracking of flamingos. Additional funds were received through an agreement between Consejería de Medio Ambiente (Junta de Andalucía) and Consejo Superior de Investigaciones Científicas, partially funded by the European Union. During manuscript preparation we were supported by funds from project BOS2002- 04695 from Dirección General de Investigación, partially co-financed with FEDER funds from the European Union. We appreciate very much the technical assistance of Antonio J. Pérez-Rodríguez with the scanner-logger. Antonio Arroyo, Rafael Camarena, Alan R. Johnson, Juan Rubio, Nico Varo and Manuel Vázquez assisted us during field work. We also thank Álvaro Muñoz for sexing flamingos using DNA analysis. The manuscript benefitted from the comments of Felicity Arengo, Arnaud Béchet, Andy J. Green, Alan R. Johnson and anonymous referees.

\section{References}

Amezaga, J.M., Santamaría, L., Green, A.J., 2002. Biotic wetland connectivity - supporting a new approach for wetland policy. Acta Oecologica 23, 213-222.
Arengo, F., Baldassarre, G.A., 1999. Resource variability and conservation of American flamingos in coastal wetlands of Yucatán, Mexico. Journal of Wildlife Management 63, 1201-1212.

Argos, 2003. Argos user's manual. Online, URL: http://www.cls.fr.

Baldassarre, G.A., Arengo, F., 2000. A review of the ecology and conservation of Caribean flamingos in Yucatán, Mexico. Waterbirds 23 (Special Publication 1), 70-79.

Berrow, S.D., Croxall, J.P., 2001. Provisioning rate and attendance patterns of wandering albatrosses at Bird Island, South Georgia. Condor 103, 230-239.

Berry, H.H., 1975. South West Africa. In: Kear, J., Duplaix-Hall, N. (Eds.), Flamingos. T. \& A.D. Poyser, Berkhamsted, pp. 53-60.

Bertault, G., Joulia, D., Johnson, A.R., Raymond, M., 1999. Sex determination in greater flamingo chicks through DNA analysis. Waterbirds 22, 282-284.

Briers, R.A., 2002. Incorporating connectivity into reserve selection procedures. Biological Conservation 103, 77-83.

Brown, L.H., 1975. East Africa. In: Kear, J., Duplaix-Hall, N. (Eds.), Flamingos. T. \& A.D. Poyser, Berkhamsted, pp. 38-48.

Casgrain, P., Legendre, P. 2001. The R Package for Multivariate and Spatial Analysis, Version 4.0d5. User's Manual. Department de Sciences Biologiques, Université de Montréal. Online, URL: http:// www.umontreal.ca/BIOL/legendre/.

Cézilly, F., Tourenq, C., Johnson, A., 1994. Variation in parental care with offspring age in the greater flamingo. Condor 96, 809-812.

Cramp, S., Simmons, K.E.L., 1977. The Birds of the Western Palearctic, vol. 1. Oxford University Press, Oxford.

Dobson, A., Rails, K., Foster, M., Soulé, M.E., Simberloff, D., Doak, D., Estes, J.A., Mills, S., Mattson, D., Dirzo, R., Arita, H., Ryan, S., Norse, E.A., Noss, R.F., Johns, D., 1999. Corridors: reconnecting fragmented landscapes. In: Soulé, M.E., Terborgh, J. (Eds.), Continental Conservation. Scientific Foundations of Regional Reserve Networks. Island Press, Washington, DC, pp. 129-170.

Figuerola, J., Green, A.J., 2002. Dispersal of aquatic organisms by waterbirds: a review of past research and priorities for future studies. Freshwater Biology 47, 483-494.

Godfrey, J.D., Bryant, D.M., Williams, M.J., 2003. Radio-telemetry increases free-living energy costs in the endangered takahe Porphyrio mantelli. Biological Conservation 114, 35-38.

Haig, S.M., Mehlman, D.W., Oring, L.W., 1998. Avian movements and wetland connectivity in landscape conservation. Conservation Biology 12, 749-758.

Harrington, B.A., Brown, S.C., Corven, J., Bart, J., 2002. Collaborative approaches to the evolution of migration and the development

of science-based conservation in shorebirds. Auk 119, 914-921. Hays, G.C., Åkesson, S., Godley, B.J., Luschi, P., Santidrian, P., 2001. The implications of location accuracy for the interpretation of satellite-tracking data. Animal Behaviour 61, 1035-1040.

Johnson, A.R., 1997. Long-term studies and conservation of greater flamingos in the Camargue and the Mediterranean. Colonial Waterbirds 20, 306-315.

McCulloch, G., Aebischer, A., Irvine, K., 2003. Satellite tracking of flamingos in southern Africa: the importance of small wetlands for management and conservation. Oryx 37, 480-483.

Rendón, M.A., Garrido, A., Ramírez, J.M., Rendón-Martos, M., Amat, J.A., 2001. Despotic establishment of breeding colonies of greater flamingos, Phoenicopterus ruber, in southern Spain. Behavioral Ecology and Sociobiology 50, 55-60.

Rendón-Martos, M. 1996. La laguna de Fuente de Piedra en la dinámica de la población de flamencos (Phoenicopterus ruber roseus) del Mediterráneo occidental. Ph.D. thesis, University of Málaga.

Rendón-Martos, M., Vargas, J.M., Rendón, M.A., Garrido, A., Ramírez, J.M., 2000. Nocturnal movements of breeding greater flamingos in southern Spain. Waterbirds 23 (Special Publication 1), 9-19. 
Simmons, R.E., 1996. Population declines, viable breeding areas, and management options for flamingos in southern Africa. Conservation Biology 10, 504-514.

Simmons, R.E., 2000. Declines and movements of lesser flamingos in Africa. Waterbirds 23 (Special Publication 1), 40-46.

Tavecchia, G., Pradel, R., Boy, V., Johnson, A.R., Cézilly, F., 2001. Sex- and age-related variation in survival and cost of first reproduction in greater flamingos. Ecology 82, 165-172.

Taylor, P.O., Fahrig, L., Henein, K., Merriam, G., 1993. Connectivity is a vital element of landscape structure. Oikos 68, 571-572.
Webster, M.S., Marra, P.P., Haig, S.M., Bensch, S., Holmes, R.T., 2002. Links between worlds: unravelling migratory connectivity. Trends in Ecology \& Evolution 17, 76-83.

Weimerskirch, H., Cherel, Y., Cuenot-Chaillet, F., Ridoux, V., 1997. Alternative foraging strategies and resource allocation by male and female wandering albatrosses. Ecology 78, 2051-2063.

White, N.A., Sjöberg, M., 2002. Accuracy of satellite positions from free-ranging grey seals using Argos. Polar Biology 25, 629-631.

With, K.A., 1994. Ontogenetic shifts in how grasshoppers interact with landscape structure: an analysis of movements patters. Functional Ecology 8, 477-485. 